\title{
Advantages of Azithromycin Over Erythromycin in Improving the Gastric Emptying Half-Time in Adult Patients With Gastroparesis
}

\author{
Jean M Larson, MD ${ }^{1}$, Anna Tavakkoli, BS ${ }^{1}$, Walter E Drane, MD², Phillip P Toskes, MD ${ }^{1}$ and Baharak Moshiree, MD, MS ${ }^{1 *}$ \\ ${ }^{1}$ Division of Gastroenterology, Hepatology and Nutrition, University of Florida, Gainesville, Florida, USA, ${ }^{2}$ Department of Radiology, University \\ of Florida, Gainesville, Florida, USA
}

\section{Background/Aims}

Current therapy for gastroparesis with prokinetic agents is limited by options and side effects. One macrolide, erythromycin (ERY), is associated with possible sudden cardiac death from QT prolongation due to P450 iso-enzyme inhibition. An alternative, azithromycin (AZI), lacks P450 inhibition. We compared the effect on gastric emptying half-times ( $t 12 / 2)$ between AZI and ERY in patients diagnosed with gastroparesis by gastric emptying scintigraphy.

\section{Methods}

Patients stopped medications known to affect gastric emptying prior to the study, and then ingested 1 scrambled egg meal labeled with 18.5-37 MBq of technetium-99m sulfur colloid followed by continuous imaging for 120 minutes, at 1 minute per frame. A simple linear fit was applied to the rate of gastric emptying, and gastric emptying $t \frac{1}{2}$ was calculated (normal $=45-90$ minutes). At 75-80 minutes, if the stomach had clearly not emptied, patients were given either ERY $(n=60)$ or AZI $(n=$ 60) $250 \mathrm{mg} \mathrm{IV}$ and a new post-treatment gastric emptying t $1 / 2$ was calculated.

\section{Results}

Comparison of gastric emptying $t^{1} \frac{2}{2}$ showed a similar positive effect (mean gastric emptying $t^{1} \frac{2}{2}$ for $A Z I=10.4 \pm 7.2$ minutes; mean gastric emptying $t^{1} / 2$ for ERY $=11.9 \pm 8.4$ minutes; $p=0.30$ ).

\section{Conclusions}

AZI is equivalent to ERY in accelerating the gastric emptying of adult patients with gastroparesis. Given the longer duration of action, better side effect profile and lack of P450 interaction for AZI as compared with ERY, further research should evaluate the long term effectiveness and safety of AZI as a gastroparesis treatment.

(J Neurogastroenterol Motil 2010;16:407-413)

Key Words

Azithromycin; Gastric emptying; Gastroparesis

Received: August 26, 2010 Revised: October 7, 2010 Accepted: October 7, 2010

(c) This is an Open Access article distributed under the terms of the Creative Commons Attribution Non-Commercial License (http://creativecommons org/licenses/by-nc/3.0) which permits unrestricted non-commercial use, distribution, and reproduction in any medium, provided the original work is properly cited.

*Correspondence: Baharak Moshiree, MD, MS

Division of Gastroenterology, Hepatology and Nutrition, University of Florida, 1600 SW Archer Rd, Gainesville, Florida 32610, USA

Tel: +1-352-273-9400,Fax: +1-352-392-3618, E-mail: moshib@medicine.ufl.edu

Financial support: This study was supported by Clinical and Translational Science Institute, NIH Grant number 1 UL1RR029890.

Conflicts of interest: None. 


\section{Introduction}

Gastroparesis (GP) or "delayed gastric emptying" is a chronic gastrointestinal motility disorder of rising prevalence and cost. ${ }^{1-7} \mathrm{GP}$ results from the impaired transit of intraluminal contents of the stomach into the duodenum in the absence of mechanical gastric outlet obstruction. ${ }^{1}$ The most common etiologies of GP are diabetes, post-surgical, medication-induced, idiopathic or post-viral infection causing functional dyspepsia. These conditions are part of a spectrum of clinical conditions, which range from the minimal delay of gastric emptying seen in functional dyspepsia to the profound delay caused by neurological dysfunction associated in long-standing diabetes. ${ }^{2-17}$ Symptom presentation in GP varies and can include early satiety, nausea and vomiting, abdominal pain, bloating and worsening gastroesophageal reflux. Moreover, GP patients are at significant risk for malnutrition due to severe weight loss from chronic nausea and vomiting leading to increased healthcare costs from work days lost to multiple ED visits or hospitalizations for symptom management. ${ }^{2-17}$ Compared with hospital admissions for other upper gastrointestinal illnesses, GP patients typically have more co-morbidities, undergo more inpatient procedures, experience a longer length of stay with higher total charges, and have an increased rate of inpatient death. ${ }^{2}$ Given these trends, effective treatments for GP are increasingly important.

Currently, erythromycin (ERY) is the most widely accepted and potent treatment for GP. ${ }^{17,18}$ ERY is a macrolide antibiotic that accelerates gastric emptying to promote the dumping of food and undigested material from the stomach into the duodenum. The prokinetic effects of ERY are well documented and partially attributed to agonist effects on smooth muscle motilin receptors. ${ }^{19-23}$ ERY is the most potent prokinetic for treatment of GP symptoms such as nausea, vomiting and abdominal pain. ${ }^{1,17,18}$ In fact, ERY is $30 \%-60 \%$ more effective in gastric emptying than other prokinetic agents, such as metoclopramide, cisapride and domperidone. $^{24}$

Despite the known benefits of ERY, a major problem is the association of this drug with an increased risk of cardiac arrhythmias. First, both IV and oral ERY lead to an increased QT interval reflecting prolongation of cardiac repolarization, predisposing patients to torsades de pointes and sudden cardiac death. ${ }^{25-31}$ Second, ERY interacts with other drugs to increase the risk of cardiac arrhythmias. In one study, patients taking ERY exhibited a 2-fold increase in the adjusted rate of sudden cardiac death when compared with untreated patients. ${ }^{25}$ The rate of sudden cardiac death was increased 5-fold in the presence of potent inhibitors of cytochrome P450 3A (CYP3A) isozymes, such as calcium channel blockers, statins and selective serotonin reuptake inhibitors. The proposed mechanism of these drugs is that the plasma level of ERY, a known substrate of CYP3A isozymes, is increased significantly upon CYP3A inhibition, resulting in an increased risk of serious cardiac arrhythmias. Unlike ERY however, azithromycin (AZI) does not interact with the CYP3A isoenzymes and is not involved in significant drug-drug interactions. ${ }^{32,33}$ The prior findings make ERY a less attractive option for many GP patients.

Recently our group used antroduodenal manometry to show that AZI is promising as an alternative to ERY for treating GP. ${ }^{1}$ Here, we extend this finding by using provocative testing with gastric emptying scintigraphy, the gold standard for diagnosis of GP. ${ }^{34}$ We hypothesized that both AZI and ERY are equivalent in improving the gastric emptying $t^{1} / 2$ in patients during the provocative phase of their gastric emptying scintigraphy (GES) due to the fact that both medications are motilin agonists and should act similarly to promote gastric emptying.

\section{Materials and Methods}

\section{Study design}

This study is a retrospective case-control analysis of 120 patients who underwent GES with provocative testing at the University of Florida department of Nuclear Medicine from July to November 2009. Patients were evaluated for chronic abdominal pain or suspected GP. The research protocol was approved by the University of Florida Health Science Center Institutional Review Board.

\section{Data/patient selection}

Consecutive patients with chronic abdominal pain or suspected GP ( $n=120)$ underwent GES performed as part of their diagnostic medical workup. All patients underwent a physical examination prior to GES to exclude any mechanical obstruction. None of the patients received narcotic analgesics for 48 hours prior to the study. We excluded patients with a history of obstruction, psychiatric or eating disorders, a macrolide allergy or malignancy. In addition, patients with systemic diseases other than diabetes or collagen vascular diseases were also excluded. Once diagnosed with GP by GES, the patients received either IV 
ERY or IV AZI depending on the availability of the medication in the pharmacy for the provocative testing phase of GES.

\section{Gastric emptying scintigraphy technique}

Patients stopped all medications known to affect gastric emptying 48 hours prior to the study. Patients then underwent GES by consuming a meal of one whole scrambled egg ( 85 calories) with 2 pieces of white bread (133 calories)/ 1 pat of butter (36 calories) and $50-100 \mathrm{~cm}^{3}$ of water for a total calorie count of 254 calories. The meal was labeled with 18.5-37 MBq of technetium$99 \mathrm{~m}$ sulfur colloid. The imaging was performed using either a single-headed gamma camera, equipped with a low-energy high resolution collimator or a dual-headed camera. Both cameras were positioned in the left anterior oblique position to minimize the effects of varying gastric attenuation on the quantitation of the gastric emptying rate. Gastric emptying was followed by continuous imaging for 120 minutes at 1 minute per frame. We set a linear rate of emptying to the data from 0-75 minutes and obtained an extrapolated half-time of emptying (normal $\mathrm{t}^{1} / 2=$ 45-90 minutes). Normal values for this meal and imaging methodology were obtained by one of the authors using 60 normal volunteers (age range: 26-60) in 1981-1982 at Henry Ford Hospital (WED personal communication, not published). Since gastric emptying follows zero order kinetics, the rate was effectively determined prior to 75 minutes. Unless the stomach clearly emptied, a prokinetic drug was given. All patients in our study were given either $250 \mathrm{mg}$ of IV ERY $(\mathrm{n}=60)$ or IV AZI $(\mathrm{n}=60)$ infused over 20 minutes at 75-80 minutes with 15 minutes of further imaging to determine the new post-drug gastric emptying half-time. AZI was utilized for provocative testing because its potential prokinetic effects were already known, and there was a national shortage of IV ERY, such that IV ERY was simply unavailable. This switch to AZI was made for several months when IV ERY simply could not be obtained.

\section{Statistical methods}

The gastric emptying data obtained during from the provocative testing were compared using a 2 tailed $t$ test with SPSS 18 software. All values are expressed as a mean $\pm \mathrm{SD}$. The null hypothesis was constructed with the assumption that no significant difference would be seen between IV ERY and IV AZI in patients during the provocative phase of their GES.
Table 1. Baseline Characteristics of the Azithromycin and Erythromycin Groups

\begin{tabular}{lccc}
\hline & Azithromycin & Erythromycin & p-value \\
\hline Age (mean $\pm \mathrm{SD}, \mathrm{yr})$ & $47 \pm 17$ & $48 \pm 15$ & 0.64 \\
Males (n) & 14 & 12 & 0.66 \\
GES $\mathrm{I}^{1 / 2}$ prior to provocative & $178 \pm 77$ & $166 \pm 68$ & 0.36 \\
testing (mean $\pm \mathrm{SD}$, min) & & & \\
Diagnosis (n) & & & \\
$\quad$ Gastroesophageal reflux disease & 24 & 30 & 0.28 \\
$\quad$ Irritable bowel syndrome & 2 & 2 & 0.65 \\
Cirrhosis & 5 & 13 & 0.04 \\
Hypothyroidism & 9 & 7 & 0.41 \\
Chronic pancreatitis & 2 & 5 & 0.25 \\
$\quad$ Diabetes & 14 & 13 & 0.83 \\
Patient symptoms (n) & & & \\
$\quad$ Chronic abdominal pain & 38 & 31 & 0.20 \\
$\quad$ Nausea and vomiting & 29 & 33 & 0.47 \\
$\quad$ Weight loss & 2 & 3 & 0.65 \\
Abdominal distention/bloating & 10 & 12 & 0.64 \\
$\quad$ Constipation & 5 & 5 & 0.25 \\
\hline
\end{tabular}

GES, gastric emptying scintigraphy.

\section{Results}

Patients in the ERY and AZI groups were closely matched for baseline characteristics by age, gender, symptoms at presentation and diagnoses prior to the study (Table 1). In the ERY group, the mean age was $47 \pm 17$ years with an age range of 21-71 years. In the AZI group, the mean age was $48 \pm 15$ years with an age range of 14-80 years. Symptoms on presentation in this group were similarly matched in number to the ERY group (Table 1). Prior surgeries in both these groups included orthoptic liver transplantation, cholecystectomy, umbilical hernia repair, Nissen fundoplication, gastric bypass, appendectomy, repair of a liver laceration and splenectomy. Statistical analysis showed no significant difference with the exception that cirrhotic patients were higher in number in the ERY group as compared to AZI. The gastric emptying $t^{1} / 2$ was similar for both groups with a mean gastric emptying $\mathrm{t}^{1} \frac{1}{2}$ for $\mathrm{ERY}=166 \pm 68$ minutes and a mean gastric emptying $\mathrm{t}^{1} / 2$ for AZI $=178 \pm 77$ minutes. Gastric emptying $\mathrm{t}^{1 / 2}$ in patients receiving either ERY or AZI showed a similar positive effect with a mean gastric emptying $t^{1} / 2$ for AZI = $10.4 \pm 7.2$ minutes and a mean gastric emptying $t^{1} / 2$ for $\mathrm{ERY}=$ $11.9 \pm 8.4$ minutes. No significant difference was found between IV AZI and IV ERY for either group with a $\mathrm{p}=0.30$ (Fig. 2). No adverse or side effects were reported by either group during the provocative phase of our gastric emptying study. 
A

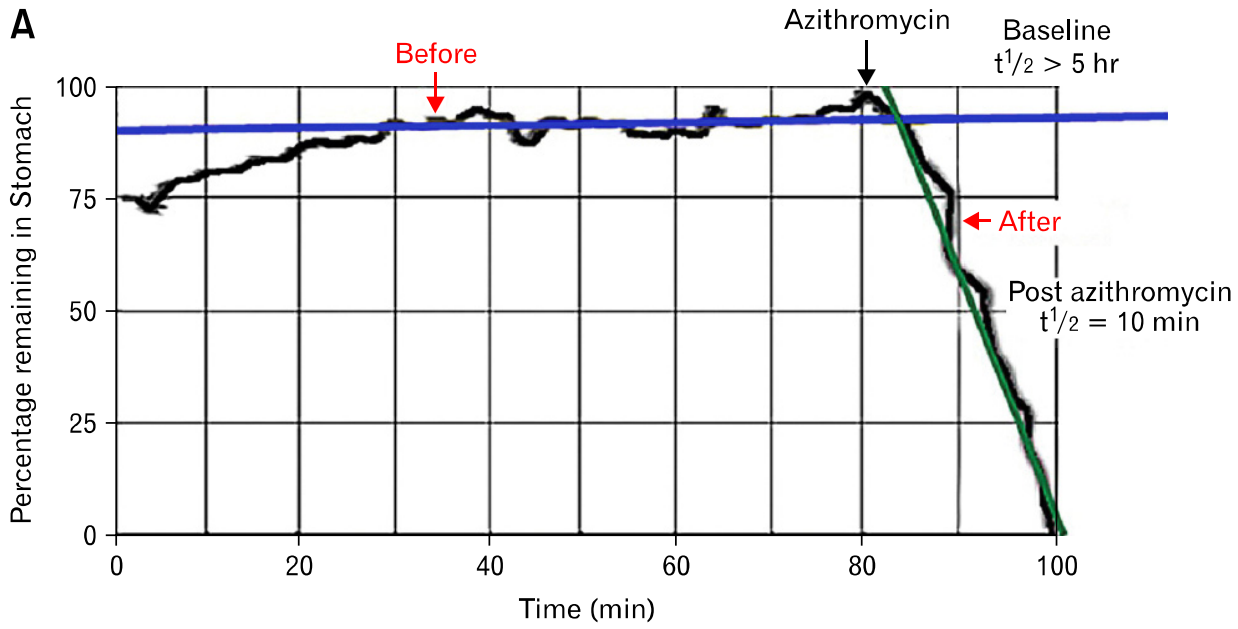

B

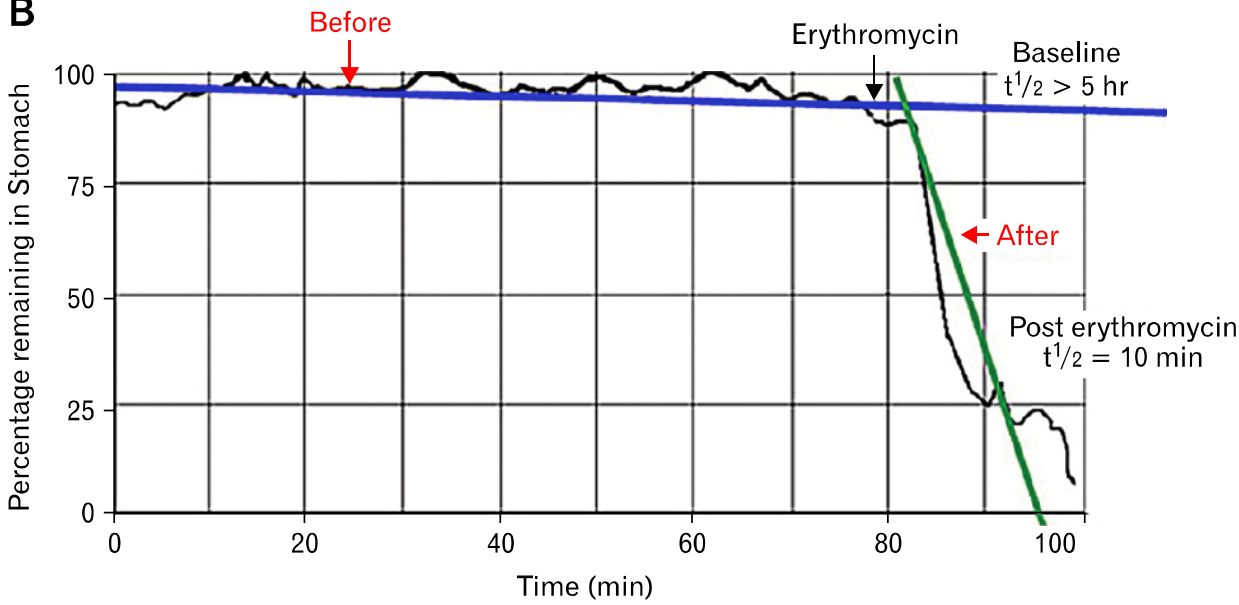

Figure 1. Azithromycin (A) and erythromycin (B) accelerated gastric emptying as measured by gastric emptying scintigraphy. Simple linear fits were applied to obtain the gastric emptying $\mathrm{t}^{1} / 2$ before and after provocative testing. GES, gastric emptying scintigraphy.

\section{Discussion}

The rising prevalence and cost of GP, as well as increasing evidence of cardiac arrhythmias and drug-drug interactions related to ERY has stimulated interest in developing new treatments for GP. In addition, the recent FDA black box warning for tardive dyskinesia for metoclopramide makes the need for new alternatives for GP even more critical. As a result, we sought to study an alternative macrolide, AZI for possible treatment of GP patients. We found that ERY and AZI have a similar positive effect on gastric emptying $t^{1 / 2}$ during the provocative testing phase of gastric emptying scintigraphy. This result supports the use of AZI as a viable alternative to ERY for treating GP, as well as findings from a previous study and case report suggesting a role for AZI in the treatment of GP. ${ }^{35,36}$ AZI could also be used during provocative testing with GES to evaluate response to this novel prokinetic that has never previously been used in the literature for such a purpose.

Moreover, our study further expands on the recent findings from our institution with antroduodenal manometry which showed that AZI stimulated antral motility in a manner similar to ERY, but with a longer duration of action for patients with chronic functional abdominal pain and GP. ${ }^{1}$ Furthermore, our results have clinical significance for GP patients due to the adverse side-effect profile for ERY, and the recent evidence that drug-drug interactions between ERY and CYP3A inhibitors lead to increased risk of cardiac arrhythmias and sudden cardiac death. In comparison to ERY and other macrolides currently available, AZI is a 15-membered semi-synthetic macrolide known to have fewer gastrointestinal side effects, better compliance and a lower cardiac risk profile compared to ERY. ${ }^{25,32}$ The lower cardiac risk profile is attributed to the lack of inhibition by AZI of the CYP3A isozymes, and minimal interaction with other CYP3A 


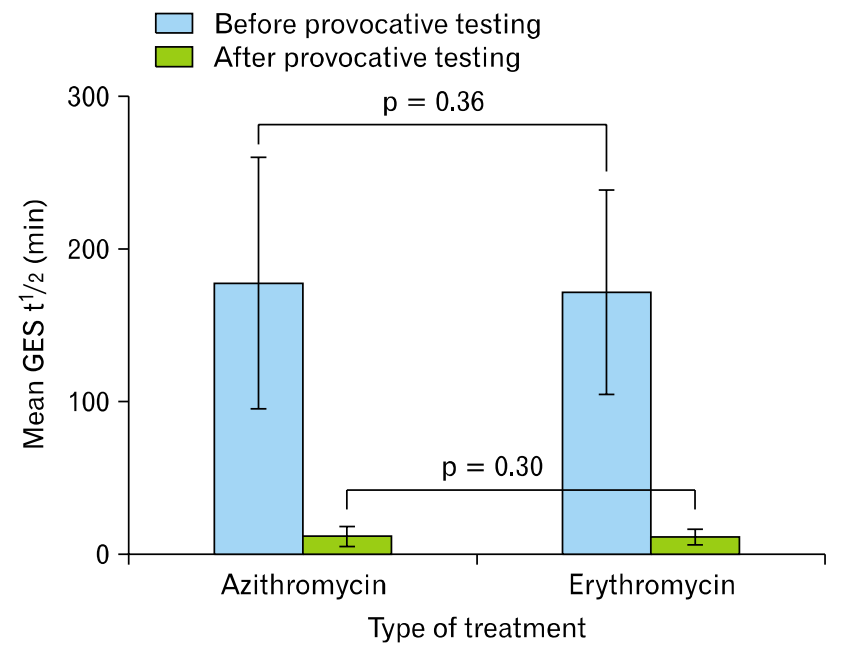

Figure 2. Comparison of the effect of azithromycin and erythromycin on gastric emptying half-times during gastric emptying nuclear scintigraphy. GES, gastric emptying scintigraphy.

inhibitors thus avoiding the clinically significant drug-drug interactions associated with ERY. ${ }^{32,33}$ Furthermore, in a study comparing ERY, clarithromycin and AZI, both ERY and clarithromycin were associated with early after depolarizations and torsades de pointes at lower $\mathrm{K}^{+}$concentrations, but AZI showed no association at all. ${ }^{35}$ In addition, AZI also appeared to have the lowest pro-arrhythmic potential of the 3 macrolides compared. ${ }^{35}$ However, AZI has been implicated in QT prolongation and torsades de pointes in isolated case reports of elderly patients on AZI. ${ }^{36-38}$ These reports prompted a year long prospective randomized control trial where patients received either AZI or placebo. The study concluded that while AZI was not effective for secondary prevention of coronary events, no increased risk of cardiac events was observed in patients on AZI. ${ }^{39}$

In addition to the better cardiac side effect profile and fewer drug-drug interactions, another potential advantage of using AZI rather than ERY is the lower frequency of side effects reported by patients on AZI. ${ }^{40}$ Frequently patients taking ERY report nausea, vomiting and diarrhea. These side effects are reported much less frequently in patients on AZI, increasing the likelihood of long-term patient compliance with AZI therapy. ${ }^{40}$ In addition to the lower incidence of side effects reported, AZI also has a longer duration of action, is absorbed well regardless of food intake, and has a higher bioavailability. ${ }^{33,40}$ This higher bioavailability gives AZI an extensive distribution throughout the body while at the same time, limiting central nervous system penetration. Finally, the longer half life of AZI of approximately 68 hours may permit once daily dosing as compared to the dosing of ERY which is required four times a day. Thus, once daily dosing in combination with fewer drug-drug interactions, and the lower incidence of side effects seen with AZI may improve patient compliance with this medication.

Despite these potential benefits of AZI, this study has some limitations. First, our study was a retrospective analysis done in one tertiary care center and could not account for potential bias that may be associated with the generalisability of that design. In addition, the study was conducted with one-time administration of drug and did not include any assessment of symptom response. In addition, although we used nuclear medicine GES which is regarded as the gold standard test, gastric emptying times have a high day-to-day variability limiting oral drug testing on 2 separate days except for large "pooled data". The new proposed standard for GES involves only three data points, limiting the testing of IV drug response. Therefore we used same day dynamic imaging with IV drug challenge. Finally, because our study only measured response in gastric emptying time after one dose of either IV ERY or IV AZI, the study could not account for the possible development of tachyphylaxis which has been observed both in patients on chronic ERY and in patients treated with short-term IV ERY.

Finally, our study has several important strengths. We use GES, which is the gold standard test; to both confirm the diagnosis of GP, and to compare responses of IV ERY and IV AZI on gastric emptying times. Furthermore, by demonstrating the equivalency of AZI and ERY in accelerating gastric emptying times, our study supports the possibility that AZI may be a viable alternative to ERY for the treatment of GP. It is also noteworthy that ERY is not being produced in the liquid formulation save for use in pediatric patients and this lack of availability of the more effective liquid suspension has limited use of ERY. In addition, in our extensive clinical experience with AZI, we have found AZI to be very effective for the symptomatic treatment of patients with GP in those who have failed on both metoclopramide and ERY (unpublished observations). Our results certainly justify a larger randomized control study with a placebo arm to further evaluate the efficacy and safety of AZI in the treatment of GP and for assessment of gastric emptying response to IV infusion of AZI during provocative testing with GES. Ultimately, these further studies will help to determine if AZI will prove to be an effective and well-tolerated treatment for GP. 


\section{References}

1. Moshiree B, McDonald R, Hou W, Toskes PP. Comparison of the effect of azithromycin versus erythromycin on antroduodenal pressure profiles of patients with chronic functional gastrointestinal pain and gastroparesis. Dig Dis Sci 2010;5 5:675-683.

2. Wang YR, Fisher RS, Parkman HP. Gastroparesis-related hospitalizations in the United States: trends, characteristics, and outcomes, 1995-2004. Am J Gastroenterol 2008;103:313-322.

3. Kassander P. Asymptomatic gastric retention in diabetics (gastroparesis diabeticorum). Ann Intern Med 1958;48:797-812.

4. Parkman HP, Hasler WL, Fisher RS; American Gastroenterological Association. Americal Gastroenterological Association technical review on the diagnosis and treatment of gastroparesis. Gastroenterology 2004;127:1592-1622.

5. Abell TL, Bernstein RK, Cutts T, et al. Treatment of gastroparesis: a multidisciplinary clinical review. Neurogastroenterol Motil 2006;18: 263-283.

6. Park MI, Camilleri M. Gastroparesis: clinical update. Am J Gastroenterol 2006;101:1129-1139.

7. Camilleri M. Clinical practice. Diabetic gastroparesis. N Engl J Med 2007;356:820-829.

8. Frank L, Kleinman L, Ganoczy D, et al. Upper gastrointestinal symptoms in North America: prevalence and relationship to healthcare utilization and quality of life. Dig Dis Sci 2000;45:809-818.

9. Talley NJ, Locke GR 3rd, Lahr BD, et al. Functional dyspepsia, delayed gastric emptying, and impaired quality of life. Gut 2006;55: 933-939.

10. Enck P, Rathmann W, Spiekermann M, et al. Prevalence of gastrointestinal symptoms in diabetic patients and non-diabetic subjects. Z Gastroenterol 1994;32:637-641.

11. Horowitz M, Harding PE, Maddox AF, et al. Gastric and oesophageal emptying in patients with type 2 (non-insulin-dependent) diabetes mellitus. Diabetologia 1989;32:151-159.

12. Bytzer P, Talley NJ, Leemon M, Young LJ, Jones MP, Horowitz M. Prevalence of gastrointestinal symptoms associated with diabetes mellitus: a population-based survey of 15,000 adults. Arch Intern Med 2001;161:1989-1996.

13. Horowitz M, O'Donovan D, Jones KL, Feinle C, Rayner CK, Samsom M. Gastric emptying in diabetes: clinical significance and treatment. Diabet Med 2002;19:177-194.

14. Jian R, Ducrot F, Ruskone A, et al. Symptomatic, radionuclide and therapeutic assessment of chronic idiopathic dyspepsia. A double-blind placebo-controlled evaluation of cisapride. Dig Dis Sci 1989;34:657-664.

15. Sarnelli G, Caenepeel P, Geypens B, Janssens J, Tack J. Symptoms associated with impaired gastric emptying of solids and liquids in functional dyspepsia. Am J Gastroenterol 2003;98:783-788.

16. Talley NJ, Vakil NB, Moayyedi P. American gastroenterological association technical review on the evaluation of dyspepsia. Gastroenterology 2005;129:1756-1780.

17. Soykan I, Sivri B, Sarosiek I, Kiernan B, McCallum RW. Demography, clinical characteristics, psychological and abuse profiles, treatment, and long-term follow-up of patients with gastroparesis.
Dig Dis Sci 1998;43:2398-2404.

18. Janssens J, Peeters TL, Vantrappen G, et al. Improvement of gastric emptying in diabetic gastroparesis by erythromycin. Preliminary studies. N Engl J Med 1990;322:1028-1031.

19. Hasler WL, Heldsinger A, Chung OY. Erythromycin contracts rabbit colon myocytes via occupation of motilin receptors. Am J Physiol 1992;262:G50-G55.

20. Sarna SK, Soergel KH, Koch TR, et al. Gastrointestinal motor effects of erythromycin in humans. Gastroenterology 1991;101:1488-1496.

21. Tomomasa T, Kuroume T, Arai H, Wakabayashi K, Itoh Z. Erythromycin induces migrating motor complex in human gastrointestinal tract. Dig Dis Sci 1986;31:157-161.

22. Itoh Z, Nakaya M, Suzuki T, Arai H, Wakabayashi K. Erythromycin mimics exogenous motilin in gastrointestinal contractile activity in the dog. Am J Physiol 1984;247:G688-G694.

23. Annese V, Janssens J, Vantrappen G, et al. Erythromycin accelerates gastric emptying by inducing antral contractions and improved gastroduodenal coordination. Gastroenterology 1992;102:823-828.

24. Sturm A, Holtmann G, Goebell H, Gerken G. Prokinetics in patients with gastroparesis: a systematic analysis. Digestion 1999;60: 422-427.

25. Ray WA, Murray KT, Meredith S, Narasimhulu SS, Hall K, Stein $\mathrm{CM}$. Oral erythromycin and the risk of sudden death from cardiac causes. N Engl J Med 2004;351:1089-1096.

26. Wisialowski T, Crimin K, Engtrakul J, O'Donnell J, Fermini B, Fossa AA. Differentiation of arrhythmia risk of the antibacterials moxifloxacin, erythromycin, and telithromycin based on analysis of monophasic action potential duration alternans and cardiac instability. J Pharmacol Exp Ther 2006;318:352-359.

27. Milberg P, Eckardt L, Bruns HJ, et al. Divergent proarrhythmic potential of macrolide antibiotics despite similar QT prolongation: fast phase 3 repolarization prevents early afterdepolarizations and torsade de pointes. J Pharmacol Exp Ther 2002;303:218-225.

28. De Ponti F, Poluzzi E, Montanaro N. QT-interval prolongation by non-cardiac drugs: lessons to be learned from recent experience. Eur J Clin Pharmacol 2000;56:1-18.

29. Drici MD, Knollmann BC, Wang WX, Woosley RL. Cardiac actions of erythromycin: influence of female sex. JAMA 1998;280: 1774-1776.

30. Shaffer D, Singer S, Korvick J, Honig P. Concomitant risk factors in reports of torsades de pointes associated with macrolide use: review of the United States Food and Drug Administration Adverse Event Reporting System. Clin Infect Dis 2002;35:197-200.

31. Koh TW. Risk of torsades de pointes from oral erythromycin with concomitant carbimazole (methimazole) administration. Pacing Clin Electrophysiol 2001;24:1575-1576.

32. Hopkins S. Clinical toleration and safety of azithromycin. Am J Med 1991;91:40S-45S.

33. Hasler WL. Gastroparesis--current concepts and considerations. Medscape J Med 2008;10:16.

34. Abell TL, Camilleri M, Donohoe K, et al. Consensus recommendations for gastric emptying scintigraphy: a joint report of the American Neurogastroenterology and Motility Society and the Society of $\mathrm{Nu}$ clear Medicine. Am J Gastroenterol 2008;103:753-763.

35. Sifrim D, Matsuo H, Janssens J, Vantrappen G. Comparison of the effects of midecamycin acetate and azithromycin on gastrointestinal 
motility in man. Drugs Exp Clin Res 1994;20:121-126.

36. Sutera L, Dominguez LJ, Belvedere M, et al. Azithromycin in an older woman with diabetic gastroparesis. Am J Ther 2008;15:85-88.

37. Huang $\mathrm{BH}, \mathrm{Wu} \mathrm{CH}, \mathrm{Hsia} \mathrm{CP}$, Yin Chen C. Azithromycin-induced torsade de pointes. Pacing Clin Electrophysiol 2007;30:1579-1582.

38. Kezerashvili A, Khattak H, Barsky A, Nazari R, Fisher JD. Azithromycin as a cause of QT-interval prolongation and torsade de pointes in the absence of other known precipitating factors. J Interv Card Electrophysiol 2007;18:243-246.

39. Grayston JT, Kronmal RA, Jackson LA, et al. Azithromycin for the secondary prevention of coronary events. N Engl J Med 2005;352: 1637-1645.

40. Rubinstein E. Comparative safety of the different macrolides. Int J Antimicrob Agents 2001;18(suppl 1):S71-S76. 